\title{
Innovations in the Indigenous Textile Weaving Firms in Southwestern Nigeria
}

\author{
Stephen Akinade Adegbite \\ Centre for Industrial Research and Development \\ Faculty of Social Sciences, Obafemi Awolowo University \\ Ile-Ife, Osun State, Nigeria
}

Tel: 234-803-786-5536; 234-805-020-8584Ｅ-mail: steveade@oauife.edu.ng; stevenade@yahoo.com

Matthew Olugbemiga Ilori

Technology Planning and Development Unit

Faculty of Technology, Obafemi Awolowo University

Ile-Ife, Osun State, Nigeria

Tel: 234-803-402-6578Ｅ-mail: milori@oauife.edu.ng

Helen Olubunmi Aderemi

National Centre for Technology Management, Obafemi Awolowo University

Ile-Ife, Osun State, Nigeria

Tel: 234-703-359-6988Ｅ-mail: helen_aderemi@yahoo.com

Received: June 28, 2011

doi:10.5539/ijbm.v6n12p243
Accepted: August 8, $2011 \quad$ Published: December 1, 2011

URL: http://dx.doi.org/10.5539/ijbm.v6n12p243

\begin{abstract}
The study investigated technology innovations and factors influencing its upgrading in the indigenous textile weaving firms in southwestern Nigeria. Data for the survey was sourced from 300 small scale firms with $91 \%$ retrieval rate. The survey instruments which were questionnaire, interview and personal observation elicited information on the weaving process. Majority $(89 \%)$ of the respondents reported product innovations while $8 \%$ and 3\% have carried out process and organizational innovations respectively. The males (74\%) weave on the horizontal loom while female respondents $(26 \%)$ weave on the vertical loom. Most $(96 \%)$ of the firms used the manual production process while a few $(4 \%)$ have introduced some process improvements. Also, $58 \%$ of the respondents lack technical skills, technical education (87\%) and investment funds (59\%). The study concluded that lack of technical education and skills as well as adequate capital could limit the capability of respondents to adopt modern weaving techniques and innovate.
\end{abstract}

Keywords: Indigenous knowledge, Indigenous textile weaving, Small scale industry, Technology innovations

\section{Introduction}

The promotion of micro and small enterprises (MSEs) has become a popular development tool around the world. Accordingly, the Federal Government of Nigeria (FGN) has shown increasing interest in promoting entrepreneurship and innovation in indigenous MSEs especially in the textile sector. This has been achieved by the various support programmes to improve their competitiveness through enhancing technology and innovation capabilities such as upgrading product quality, improving design and packaging, and training to improve their competitiveness (Pyke, 1994). The notion is that innovation is essential for MSEs to become and remain competitive, move to higher return activities, and to grow and graduate to medium and large enterprises, thus, creating new employment opportunities (Ernst, 2004).

Recognizing the significance of the MSEs' sector, the FGN enunciated the National Economic Empowerment and Development Strategy (NEEDS) in 2003 and the Vision 20:2020 in 2007 to accelerate their development 
and growth. Similarly, the revised Industrial Policy of Nigeria in 2008 also singled out the MSEs' sector as major instruments to create a productive and vibrant private sector and reduce poverty among urban 'dwellers. These policy documents emphasised the provision of finance, training, infrastructure and upgrading of production technology among other intervention.

However, in spite of their potential to improve economic growth, MSEs impacts in Nigeria are not so obvious. They employ lower levels of techniques while their innovative activities are limited. This is largely due to the harsh environment where they operate (Adegbite, 2010). According to Ernst (2004), unreliable enforcement of contracts, excessive regulatory and administrative requirements, limited access to finance, and inadequate infrastructure services all impose disproportionately high transaction costs on MSEs for doing business generally and for innovative activity in particular. Improving competitiveness is even more crucial in the context of trade liberalization and increasing integration into the world market. Lack of adaptation and upgrading of production technology poses serious challenges, while firms that keep up or even initiate their own original improvements can be expected to perform well (Romijn 2002).

This paper is structured as follows. The next section reviewed existing works on the subject; the types of indigenous Aso-oke clothes among the Yoruba of southwestern Nigeria and the process of making Aso-oke fabrics. Section three presents the results and discussion of research findings while Section four provides the conclusion and policy recommendations.

\section{Theoretical Framework}

Technology innovation is one of the critical factors that influence firms' competitiveness in the current globalized economy whereby the traditional barriers to trade and investments are being dismantled. Government policies intended to improve national competitiveness through the performance of the industrial sector depend largely on the sector's perceived or measured characteristics, such as innovation capability (Oyelaran-Oyeyinka, 1996). Therefore, firms in developing countries like Nigeria should develop the capability to exploit the traditional available technology as a means of gaining competitive edge. This capability, otherwise referred to as innovative capability, is embedded in the set of skills and competences as well as the knowledge, resources, creativity and attitude needed to continuously generate and translate ideas into marketable new products, processes and services (Oyelaran-Oyeyinka, 1996).

Innovation in this context is all about change. Change in what is being done and the way it is being done. The first dimension has to do with what a firm makes available to the market. A change could be made in what products or services the firm offers or the way these products or services are created (Tidd et al, 1998). These are traditionally referred to as product and process innovations (Kahn and Manopichetwattana, 1989). The second dimension has to do with the degree of novelty of the innovation (Tidd et al, 1998). Novelty in this context means that the innovation could be fundamentally new to the environment; it could be incremental i.e. small additions/modifications or similar to other innovations in the industry (Oyelaran-Oyeyinka, 1996). However, the focus of the study is on incremental innovations and its impact on the resilience of the indigenous textile weaving industry in southwestern Nigeria. The study would contribute to the literature on technology innovation and indigenous knowledge in the indigenous textile weaving sector especially in southwestern Nigeria.

\section{Indigenous Yoruba "Aso-oke” Textile}

"Aso-oke" is a short form of "Aso Ilu Oke" also known as "Aso-ofi" meaning clothes from the country highland area. The literal meaning of Aso-oke is "Top Cloth". Aso-oke is an important item of clothing worn by the Yoruba of southwestern Nigeria. Indigenous Aso-oke textile is one of the most vibrant and successful textiles in the African continent. By the end of $20^{\text {th }}$ century, Aso-oke was worn by the Yoruba only at major life-circle events such as birth of a new baby, weddings, festivals, burial ceremonies and so on. At present, the fabric is more popular among both the Yoruba and other ethnic groups in Nigeria (Oloyede, 2006). The Yoruba people in southwestern Nigeria especially in major towns such as Oyo, Iseyin, Saki, Okeho, Ibadan, Lagos, Osogbo, Ijebu Ode, Abeokuta, Owo and Ado Ekiti are known for their Aso-oke weaving. However, the market for indigenous textiles has decreased with the introduction of European printed cloth ever since the mid- $20^{\text {th }}$ Century. Even though traditional hand-woven clothes are sometimes overlooked in favour of the cheaper cloth, it is still considered an important and valuable form of both clothing and art. It is possible that because there are cheaper and more convenient clothes available in the market, these textiles are considered even more valuable and special to the culture (Eicher 1976).

Clothing among the Yoruba is important in several different ways. Cloth is used to signify wealth and status, particularly those of high quality. The Yoruba people often times will cover themselves in beautiful, colourful garments that drape and fold over the body, giving the impression of a person of high stature. Both the quality of the cloth and the amount of cloth used in creating the garment determine its worth. Hand-woven garments are very valuable in the Yoruba culture. The production of Aso-oke textiles is a costly and time consuming 
procedure yet this process is part of what makes them important to this culture (Cordwell, 1983).

\section{Production of Aso-oke Textile Clothes}

\subsection{Raw Materials}

The primary raw materials for the production of Aso-oke textile clothes are cotton, dyes, local silk and bark which are used in making the threads for weaving. They are either locally sourced or imported from Tunisia, Italy, France, Japan and other Asian countries. The cotton is kept in the barn for spinning which is the process of separating the cotton seed from the wool. Locally spun and dyed indigo cotton thread is expensive and often replaced by shining metallic Lurex and brightly coloured rayon threads. This process is also known as sorting (Ajala, 2010). Patterning is another stage which helps in putting the patterns and designs on the Aso-oke. The rolled cottons are neatly inserted into the sticker through the extenders. Aso-oke strips are usually between about $14-15 \mathrm{~cm}$ and stitched together to make the desired clothes.

\subsection{Production Loom}

The operators make use of two types of looms for the production of Aso-oke. These are the upright single heddle loom also known as the broad loom used by women and the horizontal double heddle loom mostly used by men. The broad loom is a fixed vertical frame upon which the warp of the thread is held under tension to weave cloth of predetermined length of about $30-90 \mathrm{~cm}$ width to allow two or three pieces to be stitched together to make a wrap known as "Iro" for women. The fabric produced on the broad loom is known as "Kijipa". The double heddle loom used by men is a horizontal loom with unwoven warp yarns stretched out several metres in front of the weaver with heavy stone or heavy metal to maintain tension. The loom produces stripes of woven fabrics, which is about $14-15 \mathrm{~cm}$ wide. The fabrics are cut and the edges stitched together to make a larger piece of cloth which could be used for clothing or coverings.

\subsection{Weaving Accessories}

The men's horizontal loom uses more accessories and provides opportunity for the use of a variety of warp threads which often determines the types and designs of found in Aso-oke.

These accessories include Akata (propeller); Iye (long wheel); Gowu and Kokogun (rollers); Aasa (stricker); Oти (extenders); Sarin (metallic pegs); Odada and Itese (pedals); Ikeke (extender rollers); Okeke (wheel or axel); Okuku (strain holder); Sofi (perforator); Sugudu (propeller hangar); Oko (shuttle) which is canoe shape; and Agborin (staff). During patterning, the canoe reels are hinged upon the hangers on a set of metallic pegs on the ground. The reason for this is to roll the cotton into bundles. Thereafter, the actual weaving starts.

\subsection{Weaving Process}

The rolled cotton will be neatly inserted to the stricker through the extenders. The weaver will tie "Iro" (filler) onto his seat. There are two or more holes on the staff in which a small peg is tagged. On the upper hand of the "Omu" (extenders), there is "Okeke" (wheel or axle) for pulling the "Omu" up and down. There are two-step pedals under the extenders $(\mathrm{Omu})$ which the weaver presses down alternately during weaving. The pedals when pressed enable the cotton to open and the "Reeler" put through to one side while the stricker knocks the reel to and fro to another side. The stricker allows the reel to be finely set alternately (Ajala, 2010). The weaver handles the "Oko" (shuttle) throws it inside the open cotton to be received by his other hand, movement of the motor continues and faster as if the weaver is not touching it at all. The reel inside the motor will start giving a peculiar sound: sakala-si-sakala-sa. As the weaver continues this way, the cloth is weaved and gradually extends forward. The weaver uses the drawer to pull the cloth towards him and the carrier responds to the force and moves towards him while the weaver continues (Ajala, 2010).

\section{Types of Aso-oke Clothes}

There are different types of Aso-oke clothes. These include prestigious and ceremonial clothes such as Etu, Alaari and Sanyan as well as other basic and ritual clothes.

\subsection{Etu Cloth}

Etu (fowl) cloth is blue with white stripes. The strips are woven using local wild silk fibers. Thus, Etu is dyed repeatedly in traditional indigo blue dye, which is brought out at intervals for dying and stretching. In ancient times, Etu was used as important social dress by chiefs and elders among the Yoruba.

\subsection{Alaari Cloth}

Alaari cloth is crimson in colour. It is traditionally woven with locally spun silk yarns dyed in red camwood solution to achieve permanence in color fastness. The use of Alaari is not limited to a particular ceremony but traditionally used for all events among the Yoruba people. 


\subsection{Sanyan Cloth}

Sanyan is regarded as an expensive Yoruba hand-woven fabric, creamy in colour with a white stripe running through the middle of the cloth. It is traditionally produced from fibers made from the cocoons of the Anaphe silk fibers. They are hand-spun into threads, washed and soaked in corn-starch to strengthen the yarn for fabric production. This was however in ancient times. In addition, Sanyan is regarded as the most expensive of all the Yoruba woven fabrics. Thus, the Yoruba refers to it as "Baba Aso", that is father of fabrics.

\subsection{Basic Clothes}

Basic clothes are those produced for severyday use. They are made with traditional hand spun thread or with industrial threads mostly imported from Asian countries to produce lighter cloth that are used as cover clothes, casual wrappers worn to markets, baby ties, work and play clothes among others. Clothes under this category include: Kijipa or Ikale, Oja and Ala (Aremu, 1982). Kijipa is one of the most common cloths woven by women on the broadloom. It serves a number of social as well as religious functions in the society. Women use it mainly as wrapper to be worn to various places ranging from the market to religious or festive occasions. Aremu (1982) lists a number of functions of hand woven textiles among Yoruba women. According to him, Kijipa could perform a number of functions including prevention of miscarriages or cure for barrenness. Ifa priests usually prescribe the cloth for childless women or women who experience constant miscarriages. Kijipa is also believed to attract to the wearer blessings, protection, prosperity, victory and health. Kijipa is also part of the cloth forms, which makes up the costume of the Yoruba Egungun Masquerade.

However, it is not the plain woven Kijipa cloth that cures or empowers but the magical charms that have been infused in it that empower the cloth and its wearer. Anyone who goes to the priest for spiritual assistance is usually told to bring Kijipa woven in a prescribed way for the ritual exercise. Oja is another basic cloth form woven by Yoruba women. It is similar to the Itagbe mainly because of the tufts of thread, which are left on it as a decorative method when it is woven. Women use the cloth to secure their babies on their backs. Ala or Ogbo is a white cloth that is generally used as a cover cloth against the cold and mosquitoes. It also serves as a wrapper for elderly men. It is wrapped under the armpit and thrown over the shoulder. Ologba Meta, another basic cloth form is used for making buba (shirt) and trousers for men. It is also used to make hunter's outfit. Later with the introduction of formal education, the cloth form was used to make uniforms for children (Adegbite, 2010).

\section{Research Methods}

The data source of this study is a survey conducted in 2010 on 300 small scale weaving indigenous weaving enterprises in southwestern Nigeria with 10 and fewer workers. The survey instruments include questionnaire and unstructured focus group discussions. They were complemented with interview of some respondents' as well as personal observation of the weaving process. The study was carried out in eleven selected major towns of southwestern Nigeria: Oyo, Iseyin, Saki, Okeho, Ibadan, Lagos, Osogbo, Ijebu Ode, Abeokuta, Owo and Ado Ekiti. A total sample of 300 questionnaires was administered out of which $273(91 \%)$ were retrieved and found useful for analysis. The data were analysed by using descriptive statistics.

\section{Results and Discussions}

Table I shows that out of the 273 questionnaires that were retrieved and analysed, majority (38\%) of the respondents were from Oyo State, 19\% from Ekiti State and 15\% from Ogun State. The other respondents, 10\% and $8 \%$, were from Ondo and Lagos States respectively. Most (12\%) of the respondents in Oyo State were found in Iseyin; Oyo town (10\%); Ibadan (8\%); Saki $(5 \%)$ while Okeho reported 3\%. In a similar study, Olaoye (2005) also observed that Iseyin and Oyo towns are important towns for men's weaving in Yorubaland. Since the early $19^{\text {th }}$ century, they have been prominent centres of hand woven clothes in Nigeria.

The result also confirmed that Ibadan has a thriving market at "Oja Oje" (Oje Market) where weavers from various towns in the study area (Annexure 1) sell their woven Aso-oke clothes on a particular day of the week. Lloyd (1993) had earlier reported that Ibadan was noted for the sale and distribution of Aso-oke where customers from all parts of Nigeria, West Africa, and Nigerians in diaspora and even Europeans buy the clothes in commercial quantity for personal and ceremonial use. It was further observed that the "Oja Oje" market in Ibadan provide the network and linkage of indigenous weavers to the formal sector of the economy.

Table 1 further showed that $19 \%$ of the response came from Ado-Ekiti compared with Osogbo, Owo, and Ijebu-Ode which had $10 \%$ response rate each, while the least response of $6 \%$ and $8 \%$ came from Mushin in Lagos State and Abeokuta in Ogun State. The high percentage of respondents found in Ado-Ekiti and Owo were attributed by Picton and Mack (1979), Olaoye (2005) and Asakitipi (2007) to the resurgence of weaving in the towns in recent years by women who have embraced indigenous textile weaving due to the downturn in the Nigerian economy. Another major reason for the resurgence could be the presence of a textile weaving centre established by government at Ado-Ekiti where prospective weavers could acquire the knowledge and skills. The 
outcome of this study validated these findings.

\section{Socio-economic Characteristics of Respondents}

The social and economic characteristics of respondents such as gender, marital status, age and ownership structure are discussed in this section.

\subsection{Gender of Respondents}

Table II indicates that $74 \%$ of the respondents using the horizontal loom were male while only $26 \%$ using the vertical loom were female. The response supports the findings in the literature by Picton and Mack (1979) of indigenous textile weaving in southwestern Nigeria and Maegher (2007) in Ilorin, Nigeria that male entrepreneurs using the horizontal loom are more predominant in the Aso-oke weaving industry while female entrepreneurs who weave on the vertical loom were very few. In addition, the study further showed that while male respondents who weave on the horizontal loom were found in all the towns in the study area, female respondents who weave only on the vertical loom are more predominant in towns such as Ijebu-Ode, Ogun State; Owo, Ondo State; and Ado-Ekiti in Ekiti State. In summary, the few $(26 \%)$ of women weavers in the industry also confirmed the findings in the literature by Kristiansen et.al, (2003) that female entrepreneurs were generally less likely to be founders of manufacturing industries than male while Kourilsky (1980) research also showed that males have higher entrepreneurial intention than females.

\subsection{Marital Status of Respondents}

Table II presents the marital status of respondents. It shows that most (79\%) were married; $18 \%$ were single; $2 \%$ were widowed and $1 \%$ was divorced. The result which indicated that most of the respondents were married agrees with the findings by Hisrich (1988) of micro enterprises in India; the study of small scale entrepreneurs in the Netherlands by Reynolds (1999); and that of small scale industries in Nigeria by Adegbite et.al, (2006) which established that married men and women performed well in managing a business because of the social, financial and psychological support than single, divorced or widowed individuals. Married people tend to work harder because of family responsibility and social commitments. This could be a reason why most of the respondents in the study were married.

\subsection{Age of Weavers}

In Table II, the age distribution shows that most (83\%) of the respondents were between the age of 21 to 50 years whereas $13 \%$ were 51 years and above while only $4 \%$ were between the age of 10 to 20 years. The result is similar to the outcome of a research in India by Sinha (1996); in Britain by Reynolds (2000) and in Indonesia by Kristiansen (2003) where it was disclosed that individuals between 25-44 years of age were the most entrepreneurial active segment of the population and that successful entrepreneurs were relatively younger in age. The high concentration of entrepreneurs in the 25-44 years age bracket in the industry could mean that the younger generations are favourably disposed to establishing and managing indigenous weaving business which could be attributed to high rate of unemployment and underemployment in Nigeria and the lack of opportunities in other sectors of the economy. These factors may perhaps be some of the reasons for the resilience of the indigenous textile industry in spite of the near collapse of the textile firms in the formal sector of the Nigerian economy.

\subsection{Ownership Structure of Business}

The ownership structure of the firms is presented in Table II. Majority (67\%) of the firms were owned by individuals while $15 \%$ were family owned. Only $9 \%$ were owned by cooperative society; $7 \%$ were partnership and only $2 \%$ were limited liability companies. In previous studies carried out by Aluko et.al. (1972) on micro and small scale enterprises in Nigeria; Chuta and Wilcox (1985) in Burkina Faso; Soetan (1995) in Nigeria; Omisakin (1999) in Ibadan, Nigeria and Adegbite et.al (2006) in Nigeria, they also reported that on the average, about $70 \%$ of MSEs in these studies were sole proprietorship. The researchers argued that the predominance of this form of business ownership among the MSEs especially in Nigeria is due partly to the advantages of sole proprietorship such as the low investment cost and ease of entry into the business. The process and cost of formalising a business such as a limited liability company has forced many MSEs in developing countries to operate as sole proprietorship rather than limited liability companies. For instance, in Nigeria, the cost of incorporating Limited Liability Company is very high while the process is also cumbersome (Adegbite et.al, 2006).

Similarly, Adegbite (2010) further suggested that operating as sole proprietorship may limit the firm's access to capital and other resources necessary for expansion and growth. Besides, another implication of the predominance of sole proprietorship form of business is that ownership, control and management of the enterprises were vested in one person i.e. the entrepreneur who is the sole owner of the business. This means that technology innovation decisions in most of the firms were taken by one person. Hence, the decision to be 
innovative or less innovative lies with the single individual. A sole proprietor can take quick innovation decisions, employ motivated people, and have unique or scarce competencies (Noteboom, 1994). However they could also lack the competence, knowledge and skills necessary for process, product and organisational innovations.

Furthermore, the small proportion of partnership, (7\%) and Cooperative businesses (9\%) could also be due to mutual distrust among the proprietors at the level of business formation and management. Similarly, the result which showed that only $15 \%$ of respondents were family owned businesses is contrary to the findings of Bray (1968) research of weavers in Southwestern Nigeria; Lloyd (1993) study of three Yoruba weaving towns and Meagher (2007) of Aso-oke weavers in Ilorin, Nigeria that close to 30\% of the enterprises were organised along the lineage, family owned and religion-based organisation of production. This study, however, showed that the traditional family control of the Aso-oke weaving industry in southwestern Nigeria could be on the decline.

\section{Production Loom, Methods and Raw Materials}

In Table III, the response to the type of production loom used by the respondents indicates that majority (86\%) used the horizontal loom while only $14 \%$ used the vertical loom. Okeke (2005) also reported that horizontal and vertical looms are the most common in West Africa and Nigeria. Horizontal loom are narrow strip, double-heddle thread looms which are used by men while the rectangular and relatively broad, single-heddle, upright looms are generally used by women. Picton and Mack, 1979 and Maegher, 2007 study also showed that male weavers predominantly use the horizontal loom while female weavers use the vertical loom.

The production methods adopted by the respondents are presented in Table 4. Majority (96\%) of the enterprises use the manual production process while only $4 \%$ have introduced some minor improvement in their production. The production process is mostly manual and there is very little evidence of any effort to fully automate the weaving process. The problem is also compounded by the length of the horizontal loom which is spread at a distance of about 10-20 metres outside the production shed. The length of the loom makes weaving difficult during the rainy season. However, it was observed that in spite of the predominance of the manual system of production, new innovations on the loom types have been introduced. Some of these include minor adaptations on the horizontal and broad looms. For instance, through casual observation of the weaving process and interview of respondents, we noted that the traditional horizontal loom has been improved upon. Instead of the raffia palm, the loom is now made with wood of different shapes and sizes by local carpenters.

Also, due to the influence of some Yoruba Aso-oke traders who sell the clothes across the Nigerian border with countries such as Togo, Ghana and Cote D'voire, the traditional horizontal loom in areas such as Lagos, Abeokuta, Ibadan and Ijebu-Ode have added on to them extra heddles and peddles. This has increased the width of the horizontal loom from the traditional 5-6 inches to between 7-8 inches in these locations. Similarly, instead of the traditional hand spun thread, the use of electric appliances such as electric motor and winding machine was also observed in some locations where they were used to wind local and imported weaving yarn of various colours on cones prior to weaving. Taken together, these incremental innovations has reduced wastage of raw materials, substantially increased output and sales revenue for Aso-oke products.

In Table 4 the sources of raw materials is presented. Most (69\%) of the respondents used a combination of local and imported raw materials; $28 \%$ use only locally sourced materials while $3 \%$ made use of only imported raw materials. The result, including interview and observation of the weaving process, further revealed that the use of imported yarn of various colours, mostly from the Asian countries, is now common in the industry. This practice has made the clothes more colourful, stronger and durable than the traditional forms of Aso-oke. The respondents claimed that imported yarn of high quality help to reduce idle time and loss of materials during the weaving process. The reason adduced for this is that with the use of the traditional hand-spun cotton yarn, the frequency of breakage was very high. Another major advantage is that the owner of the Aso-oke can wash the cloth without the fear that the colours will run out thereby leaving the cloth faded or that the cloth will disintegrate because of the weak hand spun yarns. This is also a major incremental product innovation in the industry.

\section{Types of Innovations}

In Table $4,89 \%$ of the respondents carried out product innovations while only $8 \%$ and $3 \%$ respectively engaged in process and organisation innovations. This result is similar to the findings of Akerele (2000) who reported that among the small-scale metal fabricators in southwestern Nigeria, product innovations averaged $70 \%$ while process innovations were $30 \%$. In another study of small and medium scale manufacturing industries in southwestern Nigeria, Abereijo (2006) also reported that $70.2 \%$ of respondents engaged in product innovations while only $29.8 \%$ carried out process innovations. Product innovations create new products, while process innovations reduce the cost of producing existing products or in the production of new products (Luecke and Katz, 2003). A process innovation also refers to any new equipment, process or improved process that is 
introduced in the industry in the past three years. Similarly, organisational innovation refers to new approaches to managing or organising the firm (Davila, et.al. 2006). In this study, the result indicated a very low level of process and organisational innovations. This means that not much has been achieved in process design which may be due to the ownership structure dominated by sole proprietors who lack the technical knowledge, skills and competence necessary for process innovations. Similarly, the low level of education and capital base of enterprises in the sector could also negate their ability to engage in research and development (R\&D) activities which could be due to lack of skills and resource crunch (Oyelaran-Oyeyinka, 1996).

\subsection{Type of Product Innovations}

Table 5 presents the type of product innovations in the industry. It revealed that $76 \%$ had carried out new product formulation; $62 \%$ reported product modification and $59 \%$ were engaged in the improvement of products quality. The number of respondents who modified their products to reduce costs and change the design of product packaging was $26 \%$ and $4 \%$ respectively. The implication of this result is that there exists a high level of minor change capabilities by the firms. Moreover, the respondents have also demonstrated the ability to improve and adapt their products to satisfy the market needs. With these little process design and minor organisational adjustment, the industry has been able to achieve a high level of incremental upgrading of product design and this is evident in the modern and colourful Aso-oke products sold in the market. In Table 6, respondents were asked to describe their innovations. About $41 \%$ and $44 \%$ claimed that their product and process innovations respectively were incremental in nature; $37 \%$ and $21 \%$ reported that they are similar to others in the industry; while $11 \%$ and $16 \%$ respectively claimed that their innovations is fundamentally new to the world. Other respondents, $7 \%$ and 3\% reported that they differ from others in the industry while $4 \%$ and $16 \%$ shows that they are similar to others in the industry.

\subsection{How Innovations are Acquired}

As shown in Table 7, most (92\%) of the new innovations were through personal observation and intuition while only $(8 \%)$ are associated with intensive scientific research or R\&D efforts. Therefore, these innovations were by intuition and not associated with any research and development (R\&D) efforts. From our discussions and observations, most of the respondents had no idea of what formal R\&D is all about. According to them, virtually all the firm's knowledge base is not codified in blueprints and manuals nor could they show any evidence of the amount of resources spent on R\&D. Technical information assist firms to learn more about production technologies and helps on-the-job training and diffusion of knowledge within the firm and maintenance of quality control (Akerele 2000). This is not the case with the firms in the study.

It therefore implies that learning and the resultant skill acquired are effected through direct instructions and built over time through practice. This approach makes transfer of knowledge for process innovations very difficult. Therefore, doing process improvement becomes problematic and could be one of the factors limiting the firms' ability to engage in sustained process improvement and compete with other textile producers in the regional and international market. Similarly, lack of investment funds could also inhibit the ability of the firms to acquire new production equipments necessary for innovations and enhanced output.

\subsection{Reason(s) for not Introducing New Process Improvement}

Table 8 shows the reasons why majority of the respondents did not introduce process improvement in their operations in spite of substantial product innovations. About 58\% of the respondents reported lack of technical skills which means that lack of technical education has limited their exposure to modern weaving techniques. It also has a negative influence on their ability to introduce new process innovations. This is a reflection of lack of formal education among the respondents as only $13 \%$ of them possessed technical education. Lack of investment funds was a challenge to $19 \%$ of the respondents while $11 \%, 5 \%, 3 \%$ and $3 \%$ signified lack of serious competition; stifling government regulations; lack of investment opportunities; and inadequate investment incentives as challenges respectively.

Process improvement in the industry was also by intuition and not associated with any R\&D efforts. Many of the respondents had no idea of what formal R\&D is all about. This could be one of the factors limiting the firm's ability to engage in sustained process innovation and compete with other producers of textile clothes in the regional and international market. Lack of investment funds could also inhibit the ability of the firm to acquire new production equipments.

\section{Conclusion and Recommendations}

In this study, the result indicated a very low level of process and organisational innovations. This means that not much has been achieved in process design which may be due to the ownership structure which is dominated by sole proprietors who lack the technical knowledge, skills and competence necessary for process innovations. Similarly, the low level of education and capital base of enterprises in the sector could also negate their ability to 
engage in research and development (R\&D) activities which could be due to lack of skills and resource crunch. The study concludes that lack of technical education and skills as well as adequate capital could limit the capability of respondents to adopt modern weaving techniques. These factors, particularly lack of technical education and skills and access to capital, could negate government policy and increasing interest in promoting entrepreneurship and innovation in the indigenous textile weaving sector. Similarly, lack of efforts by operators to improve technology and innovation capabilities in the sector by upgrading production process, improving design and packaging could be a major drawback that could limit their global competitiveness within the context of trade liberalization and increasing integration into the world market.

\section{References}

Adegbite S.A. (2010). A Study of Technological Innovations in the Indigenous Textile Weaving Industry in Southwestern Nigeria. Unpublished Ph.D. Thesis submitted to Technology Planning and Development Unit (TPDU), Faculty of Technology, Obafemi Awolowo University, Ile-Ife, Nigeria.

Adegbite, S.A, Ilori, M.O., Aderemi, H.O., and Abereijo, I.O. (2006). Evaluation of the Impact of Entrepreneurial Characteristics on the Performance of Small Scale Manufacturing Industries in Nigeria. Journal of Asia Entrepreneurship and Sustainability. 111 (1): 90-123.

Ajala, O. (2010). Aso-oke: Yoruba Hand Woven Textiles. The Guardian on Saturday, October 9, 2010.

Aremu, P.S.O. (1982). Yoruba Traditional Weaving: Kijipa Motifs, Colour and Symbols. Nigerian Magazine, No. 40: 3-10.

Asakitipi, A.O. (2007). Functions of Hand Woven Textiles among Yoruba Women in Southwestern Nigeria. Nordic Journal of African Studies, 16 (1): 101-115.

Cordwell, M.J. (1983). Some Aesthetic Aspects of Yoruba and Benin Cultures. African Art, 19 (1): 21-23. http://dx.doi.org/10.2307/3336379

Eicher, J. (1976). Nigerian Handicraft Textiles. Lagos, Nigeria: The Shell Petroleum Development Company Limited.

Ernst, D. (1994). Network Transactions: Market Structure and Technology Diffusion: Implications for South-South Cooperation. In Lynn Mytelka (Ed.). South-South Cooperation in a Global Perspective. OECD Development Centre Documents, Paris.

Federal Government of Nigeria. (2004). National Economic Empowerment and Development Strategy (NEEDS). Abuja, Nigeria: Federal Government Press.

Federal Government of Nigeria. (2007). Vision 20:2020. Abuja, Nigeria: Government Press.

Federal Ministry of Industry. (2008). Industrial Policy of Nigeria. Abuja, Nigeria: Federal Government Press.

Kahn, A., and Manopichetwattana, V. (1989). Innovative and Non innovative Small Firms: Types and Characteristics. Management Science, 35 (5): 597-606. http://dx.doi.org/10.1287/mnsc.35.5.597

Kiggundu, M. N. (2002). Entrepreneurs and Entrepreneurship in Africa: What is known and needs to be done. Journal of Developmental Entrepreneurship, 7, pp. 239-258.

Kourilsky, M. L. (1980). Predictions of Entrepreneurship in a Simulated Economy. The Journal of Creative Behaviour, 14(3): 175-199.

Kristiansen, S., Furuholt, B., and Wahid, F. (2003). Internet Café Entrepreneurs: Pioneers in Information Dissemination in Indonesia. The International Journal of Entrepreneurship and Innovation, 4 (4): 251-263. http://dx.doi.org/10.5367/000000003129574315

Lloyd, P. (1993). Craft Organization in Yoruba Towns. Africa, 23: 30-44. http://dx.doi.org/10.2307/1156031

Lundvall, B.A. (1988). Innovation as an Interactive Process: From User-producer Interaction to the National System of Innovation. In G. Dosi, C. Freeman, R. Nelson, G. Silverberg and L. Soete (Eds.). Technical Change and Economic Theory. London: Pinter Publishers.

Lundvall, B.A. (1992). National Systems of Innovation: Towards a Theory of Innovation and Interactive Learning. London: Pinter Publishers.

Meagher, K. (2007). Manufacturing Disorder: Liberalization, Informal Enterprise and Economic Ungovernance in African Small Firms Clusters. Development and Change, 38 (3): 473-503. http://dx.doi.org/10.1111/j.1467-7660.2007.00420.x

Nelson, R.R. (1993). National Innovation Systems: A Comparative Analysis. New York: Oxford University Press. 
Nigerian Investment Promotion Commission. (2010). Overview of Small and Medium Scale Enterprises in Nigeria. An Information Booklet, pp.1-33.

Olaoye, R.A. (2005). Cloth Talks: A Study of Cloth Among the Yoruba in Nigeria. Africa Update Newsletter, Vol. X11, Issue 3.

Oloyede, J. (2006). Clothing in ancient Africa. [Online] Available: http://www.forumcityusa.com. (27 April, 2011).

Organization for Economic Cooperation and Development. (1992). Industrial Policy in OECD Countries. Annual Review. Paris France: OECD Press.

Oyelaran-Oyeyinka, B. (1996). The Nature, Dimension and Determinants of Industrial Innovation, Training Course on R \& D and Innovation Management, Obafemi Awolowo University, Ile-Ife, Nigeria.

Picton, J., and Mack, J. (1979). African Textiles. London: British Museum Publications Ltd.

Pyke, F. and Sengenberger, W. (Ed.). (1992). Industrial Districts and Local Economic Regeneration. Geneva: ILO: International Institute for Labour Studies, Switzerland.

Reynolds, P. (1999). Nascent Entrepreneurship in Northern Europe. in EIM (Ed.) Entrepreneurship in the Netherlands. The Hague/Zoetermer: EIM/EZ.

Romijn, H., and Albalsadejo, M. (2004). Determinants of Innovation Capability in Small UK Firms: An Empirical Analysis. Queen Elizabeth Working Paper Series. [Online] Available: http://www.qeh.ox.ac.uk. (15 March, 2011)

Tidd, J., Bessant, J., and Pavit, K. (1998). Managing Innovation: Integrating Technological, Market and Organizational Change. Chichester, UK: John Wiley and Sons.

Vision 20:2020. (2007). Publication of the Federal Government of Nigeria. Government Press, Abuja, Nigeria.

Table 1. Location of Business by States and Towns in Southwestern Nigeria

\begin{tabular}{|c|c|c|c|}
\hline No. & Location of Business & Frequency & Percent (\%) \\
\hline \multirow[t]{6}{*}{1.} & Oyo State & 103 & $38 \%$ \\
\hline & (a) Oyo & 31 & $10 \%$ \\
\hline & (b) Ibadan & 22 & $8 \%$ \\
\hline & (c) Iseyin & 29 & $12 \%$ \\
\hline & (d) Okeho & 8 & $3 \%$ \\
\hline & (e) Saki & 13 & $5 \%$ \\
\hline \multirow[t]{2}{*}{2.} & Osun State & 27 & $10 \%$ \\
\hline & (a) Osogbo & 27 & $10 \%$ \\
\hline \multirow[t]{2}{*}{3.} & Ondo State & 26 & $10 \%$ \\
\hline & (a) Owo & 26 & $10 \%$ \\
\hline \multirow[t]{2}{*}{4.} & Ekiti State & 53 & $19 \%$ \\
\hline & (a) Ado-Ekiti & 53 & $19 \%$ \\
\hline \multirow[t]{3}{*}{5.} & Ogun State & 42 & $15 \%$ \\
\hline & (a) Ijebu-Ode & 26 & $10 \%$ \\
\hline & (b) Abeokuta & 16 & $6 \%$ \\
\hline \multirow[t]{3}{*}{6.} & Lagos State & 22 & $8 \%$ \\
\hline & (a) Mushin & 22 & $8 \%$ \\
\hline & Total & 273 & $100 \%$ \\
\hline
\end{tabular}

Source: Analysis of Data, 2010. 
Table 2. Socio-economic Characteristic of Weavers

\begin{tabular}{|l|c|c|}
\hline \multirow{2}{*}{ Characteristic } & \multicolumn{2}{|c|}{ Respondents } \\
\cline { 2 - 3 } (I) Gender & Frequency & Percentage (\%) \\
Male & 203 & 74 \\
Female & 70 & 26 \\
(II) Marital Status & 216 & 79 \\
Married & 46 & 18 \\
Single & 4 & 1 \\
Divorced & 5 & 2 \\
Widowed & 12 & 4 \\
(iii) Age & 90 & 33 \\
10-20 & 84 & 31 \\
$21-30$ & 51 & 19 \\
$31-40$ & 26 & 9 \\
$41-50$ & 10 & 4 \\
$51-60$ & & 67 \\
61-70 & 182 & 7 \\
(iv) Ownership Structure & 20 & 9 \\
Sole Proprietorship & 25 & 2 \\
Partnership & 6 & 15 \\
Cooperative Society & 40 & $\mathbf{1 0 0 \%}$ \\
Limited Liability Company & $\mathbf{2 7 3}$ & \\
Family Owned Business & & \\
Total & & \\
\hline
\end{tabular}

Source: Analysis of Data, 2010.

Table 3. Type of Production Loom

\begin{tabular}{|l|c|c|c|c|}
\hline \multirow{2}{*}{ Description } & \multicolumn{2}{|c|}{ Horizontal Loom } & \multicolumn{2}{c|}{ Vertical Loom } \\
\cline { 2 - 5 } & 234 & $\mathbf{8 6 \%}$ & 39 & $\mathbf{1 4 \%}$ \\
\hline Oyo State & 60 & $22 \%$ & 3 & $1 \%$ \\
Osun State & 25 & $9 \%$ & 5 & $2 \%$ \\
Ondo State & 44 & $16 \%$ & 14 & $5 \%$ \\
Ekiti State & 57 & $21 \%$ & 5 & $2 \%$ \\
Ogun State & 33 & $12 \%$ & 12 & $4 \%$ \\
Lagos State & 15 & $6 \%$ & - & - \\
Total & $\mathbf{2 3 4}$ & $\mathbf{8 6 \%}$ & $\mathbf{3 9}$ & $\mathbf{1 4 \%}$ \\
\hline
\end{tabular}

Source: Analysis of Data, 2010.

Table 4. Production Methods; Raw Materials and Types of Innovations

\begin{tabular}{|l|c|c|}
\hline \multirow{2}{*}{ Description } & \multicolumn{2}{|c|}{ Respondents } \\
\cline { 2 - 3 } (i) Production Methods & Frequency & Percentage \\
Manual Process & 262 & $96 \%$ \\
Manual \& Semi Automated Process & 11 & $4 \%$ \\
Fully Automation Process & - & - \\
Total & $\mathbf{2 7 3}$ & $\mathbf{1 0 0 \%}$ \\
(ii) Sources of Raw Materials & 76 & $28 \%$ \\
Domestic & 7 & $3 \%$ \\
Foreign & 190 & $69 \%$ \\
Both (Domestic\&Foreign) & $\mathbf{2 7 3}$ & $\mathbf{1 0 0 \%}$ \\
Total & 243 & $89 \%$ \\
(iii)Type(s) of Innovations & 22 & $8 \%$ \\
Product & 8 & $3 \%$ \\
Process Innovations & $\mathbf{2 7 3}$ & $\mathbf{1 0 0 \%}$ \\
Organization & & \\
Total &
\end{tabular}

Source: Analysis of Data, 2010. 
Table 5. Type(s) of New Product(s) Introduced

\begin{tabular}{|l|c|c|c|c|}
\hline \multirow{2}{*}{ Description } & \multicolumn{2}{|c|}{ Frequency } & \multicolumn{2}{c|}{ Percentage } \\
\cline { 2 - 5 } & Yes & No & Yes & No \\
\hline New Product Formulation & 207 & 66 & $76 \%$ & $24 \%$ \\
Product Modification & 170 & 103 & $62 \%$ & $38 \%$ \\
Quality Improvement & 162 & 111 & $59 \%$ & $41 \%$ \\
Modification to Reduce Costs & 71 & 202 & $26 \%$ & $59 \%$ \\
Changing Packaging Design & 11 & 262 & $4 \%$ & $96 \%$ \\
\hline
\end{tabular}

Source: Analysis of Data, 2010.

Table 6. Description of Innovations

\begin{tabular}{|l|c|c|c|c|}
\hline \multirow{2}{*}{ Description } & \multicolumn{2}{|c|}{ Product Innovations } & \multicolumn{2}{c|}{ Process Innovations } \\
\cline { 2 - 5 } & Frequency & Percent & Frequency & Percent \\
\hline Incremental innovations i.e. addition, modification etc & 100 & $41 \%$ & 10 & $44 \%$ \\
Innovations that is similar to others in the industry & 99 & $37 \%$ & 5 & $21 \%$ \\
Innovations that is fundamentally new to the world & 27 & $11 \%$ & 3 & $16 \%$ \\
Innovations that differs from others in the industry & 17 & $7 \%$ & 1 & $3 \%$ \\
Innovations that is the same as others in the industry & 10 & $4 \%$ & 3 & $16 \%$ \\
Total & $\mathbf{2 5 3}$ & $\mathbf{8 9 \%}$ & $\mathbf{2 2}$ & $\mathbf{8 \%}$ \\
\hline
\end{tabular}

Source: Analysis of Data, 2010

Table 7. How Innovations are acquired

\begin{tabular}{|l|c|c|}
\hline \multirow{2}{*}{ Description } & \multicolumn{2}{|c|}{ Respondents } \\
\cline { 2 - 3 } & Frequency & $\begin{array}{c}\text { Percentage } \\
\text { (\%) }\end{array}$ \\
\hline How Innovations are acquired: & & \\
Through Personal Observation & 240 & $92 \%$ \\
Through Intensive Scientific research (R\&D) & 23 & $8 \%$ \\
Total & $\mathbf{2 7 3}$ & $\mathbf{1 0 0 \%}$ \\
\hline
\end{tabular}

Source: Analysis of Data, 2010

Table 8. Reason(s) for not introducing any New Production Process

\begin{tabular}{|l|c|c|}
\hline Description & Frequency & Percentage \\
\hline & & \\
Lack of Technical Skills & 158 & $58 \%$ \\
Lack of Investment Funds & 52 & $19 \%$ \\
No Serious Competition & 30 & $11 \%$ \\
Stiffing Government Regulations & 14 & $5 \%$ \\
Lack of Investment Opportunities & 11 & $3 \%$ \\
Inadequate Investment Incentives & 8 & $3 \%$ \\
Total & $\mathbf{2 7 3}$ & $\mathbf{1 0 0 \%}$ \\
\hline
\end{tabular}

Source: $\quad$ Analysis of Data, 2010. 